\title{
Initial experience with minimally invasive cardiac operations
}

\author{
Experiência inicial com operações cardíacas minimamente invasivas
}

Francisco Costa ${ }^{1}$, Guilherme Winter ${ }^{2}$, Andrea Dumsch de Aragon Ferreira ${ }^{3}$, Tadeu Augusto Fernandes ${ }^{2}$,
Claudinei Collatusso $^{3}$, Fernanda Tome Tremel ${ }^{4}$, Fabio Rocha Farias ${ }^{5}$, Daniele de Fátima Fornazari ${ }^{3}$

\section{Abstract}

Background: Minimally invasive cardiovascular operations have been proposed as an alternative method to correct several cardiac congenital and acquired heart diseases, with the aim to reduce morbidity and mortality.

Objectives: Describe the two years initial experience with minimally invasive operations, with emphasis on technical aspects and the learning curve.

Methods: Between July 2009 and March 2012, 95 patients were operated using minimally invasive operations. Mean age was $55 \pm 15$ years and $53 \%$ were females. The operations performed were atrial septal defect closure (25), aortic valve replacement (32), mitral valve repair (23), mitral valve replacement (12), excision of atrial myxoma (2) and resection of subaortic membrane (1). The incision was a mini right thoracotomy in 87 cases and ministernotomy in 8 .

Results: Early mortality was $4.2 \%$. Mean size of the incision was $6.3 \pm 1.2 \mathrm{~cm}$. Extension of the original thoracotomy was necessary in only one case. Two patients suffered a stroke, and the mean total blood loss was $470 \pm$ $277 \mathrm{ml}$. There were no cases of incision infection and $67 \%$ the patients had no major morbidity.
1. Titular Professor of the Medicine Department at Pontifical University of Paraná (PUCPR); Cardiovascular Surgeon, Curitiba, PR, Brasil.

2. Resident Physician in Cardiovascular Surgery at PUCPR, Curitiba, PR, Brazil.

3. Cardiovascular Surgery at PUCPR, Curitiba, PR, Brazil.

4. Student at PUCPR, Curitiba, PR, Brazil.

5. Cardiologist at PUCPR, Curitiba, PR, Brazil.

This study was performed at Pontifical Catholic University of Paraná
Conclusions: Our initial results with minimally invasive operations demonstrated that it was safe and with good clinical results. Patient satisfaction is quite high. After the learning phase has been transversed, minimally invasive operations may be an excellent alternative for many patients with congenital and acquired diseases.

Descriptors: Mitral valve. Aortic valve. Surgical procedures, minimally invasive. Heart valve diseases. Heart valve prosthesis implantation.

\section{Resumo}

Introdução: Operações cardíacas minimamente invasivas têm sido propostas como uma alternativa para a correção de diversas cardiopatias congênitas e adquiridas, com o intuito de reduzir a morbimortalidade.

Objetivos: Descrever a experiência inicial de dois anos com operações cardíacas minimamente invasivas, com ênfase nos aspectos técnicos e na curva de aprendizado.

Métodos: Entre julho de 2009 a março de 2012, 95 pacientes foram operados com técnicas minimamente invasivas. A média de idade foi de $55 \pm 15$ anos e $53 \%$

- PUCPR - Irmandade Santa Casa de Misericórdia de Curitiba, Cardiology and Nephrology Institute of Curitiba, Curitiba, PR, Brazil

Correspondence address: Francisco Costa

Rua Henrique Coelho Neto, 55 - Curitiba, PR

Brasil - CEP 82200-120

E-mail: fcosta13@me.com 


\begin{tabular}{|ll|}
\hline Abbreviations, acronyms and abbreviations \\
\hline CVA & Stroke \\
CPB & Cardiopulmonary bypass \\
ASD & Atrial septal defect \\
CO2 & Carbon dioxide \\
RICS & Right intercostal space \\
TEE & Intraoperative transesophageal echocardiography \\
AMI & Acute myocardial infarction \\
STS & Society of Thoracic Surgery \\
ICU & Intensive care unit \\
\hline
\end{tabular}

pacientes eram do sexo feminino. As operações foram fechamento de comunicação interatrial (25), substituição valvar aórtica (32), plastia mitral (23), substituição valvar mitral (12), ressecção de mixoma de átrio esquerdo (2) e ressecção de membrana subaórtica (1). A incisão consistiu de minitoracotomia lateral direita em 87 casos e de miniesternotomia em oito.

\section{INTRODUCTION}

The median thoracotomy remains the most widely used incision for the realization of most cardiac sugeries. Through it, we can have full access to the heart chambers and vessels, and perform all types of operations, including valve surgery, congenital heart diseases, tumor resection, aortic aneurysm and coronary artery bypass grafting. However, the surgical trauma involved is large considering the size of the incision and the need for complete section of the sternum, and may lead to postoperative pain, relatively long time for functional recovery, besides the possibility of serious infections [1] .

Nowadays, with wide access to information through the Internet, there is increasing demand by patients in search of less aggressive procedures. Furthermore, interventional cardiology has offered alternative solutions for the treatment of coronary failure and various valve diseases and congenital heart disease. In this context, it is natural that cardiovascular surgery seek technological developments that allow for the less invasive surgical treatment [2,3].

Minimally invasive surgeries refer to a variety of infusion techniques and visualization, allowing to perform surgeries
Resultados: A mortalidade imediata foi de $4,2 \%$, e 0 tamanho médio da incisão foi de $6,3 \pm 1,2 \mathrm{~cm}$. A extensão da toracotomia só foi necessária em um caso. Dois pacientes apresentaram acidente vascular cerebral, e a quantidade total de sangramento foi de $470 \pm 277 \mathrm{ml}$. Nenhum paciente teve infecção de ferida operatória, e $67 \%$ dos casos não apresentaram morbidade pós-operatória significativa.

Conclusões: Os resultados iniciais com operações minimamente invasivas demonstraram que elas podem ser realizadas de forma segura e com resultados iniciais satisfatórios. $O$ índice de satisfação dos pacientes foi elevado. Uma vez ultrapassada a curva de aprendizado, as operações minimamente invasivas podem ser uma excelente alternativa para muitos pacientes com cardiopatias valvares e congênitas.

Descritores: Valva mitral. Valva aórtica. Procedimentos cirúrgicos minimamente invasivos. Doenças das valvas cardíacas. Implante de prótese de valva cardíaca. with smaller incisions [4-7]. From the early 1990s, several authors began to advocate the use of these techniques, which have become the preferred approach for repair and valve replacement in a few specialized centers [1]. In theory, the use of less invasive techniques would be associated with less postoperative pain, shorter hospital stay, faster return to daily activities, top cosmetic results and possibly reduced costs [1-3]. On the other hand, there is concern that limited access may be associated with more immediate risks and the use of inferior alternative surgical techniques, as in the case of complex repair of the mitral valve [8]. Moreover, there is sufficient number of randomized controlled studies that prove, unequivocally, the real advantages of minimally invasive surgeries when compared to conventional techniques [2,3].

From June 2009, we used in selected cases minimally invasive techniques, preferably with lateral minithoracotomy for the correction of mitral and aortic valve, closure of atrial septal defects (ASD) or myxoma resection.

This study aims to show immediate results, discuss any difficulties and the learning curve encountered with the application of these techniques and their applicability in more routine valve surgeries. 


\section{METHODS}

\section{Patients}

Between July 2009 and March 2012, 95 patients underwent usrgery consecutively, using minimally invasive techniques. In this initial series, patient selection criteria included mitral and aortic valve disease in which the surgeon anticipate the use of conventional and routine techniques, such as the implantation of mechanical or bioprosthetic prostheses or non-comples mitral repair involving the posterior leaflet prolapse alone. Patients with complex mitral prolapse involving both valve leaflets or Barlow's syndrome, as well as patients with severe aortic calcification of the ascending aorta. The surgeries were performed at the Santa Casa de Misericórdia de Curitiba and Institute of Neurology and Cardiology of Curitiba (Curitiba, PR, Brazil).

The patients' ages ranged from 21 to 84 years $($ mean $=$ $55 \pm 15$ years) and 45 were male and 50 were female. The most common diagnoses that led the surgery were the aortic valve, and mitral septal defect. Most patients were preoperatively in NYHA functional class II or III and 15\% had atrial fibrillation associated. Detailed clinical characteristics of the patients are listed in Tables 1 and 2.

Table 1. Clinical characteristics of 95 patients who underwent the minimally invasive surgeries.

\begin{tabular}{|c|c|c|}
\hline $\begin{array}{l}\text { No. of patients } \\
\text { Age }(\text { mean } \pm S D)\end{array}$ & 55 & years \\
\hline Gender & & \\
\hline Male & 45 & $47 \%$ \\
\hline Female & 50 & $53 \%$ \\
\hline Electrocardiogram & & \\
\hline Sinus & 80 & $84 \%$ \\
\hline Atrial fibrillation & 15 & $16 \%$ \\
\hline Functional class - NYHA & & \\
\hline Class I & 12 & $12 \%$ \\
\hline Class II & 44 & $47 \%$ \\
\hline Class III & 29 & $31 \%$ \\
\hline Class IV & 10 & $10 \%$ \\
\hline Comorbidities & & \\
\hline Dyslipidemia & 32 & $34 \%$ \\
\hline Diabetes mellitus & 11 & $11 \%$ \\
\hline Hypertension & 64 & $67 \%$ \\
\hline Obesity & 7 & $7 \%$ \\
\hline Renal & 5 & $5 \%$ \\
\hline Smoking & 14 & $14 \%$ \\
\hline Chronic obstructive pulmonary disease & 5 & $5 \%$ \\
\hline Peripheral arterial occlusive disease & 4 & $4 \%$ \\
\hline Previous stroke & 3 & $3 \%$ \\
\hline
\end{tabular}

SD = standard deviation. NYHA = New York Heart Association
Table 2. Diagnostic data in 95 patients who underwent minimally invasive surgeries

\begin{tabular}{lcc}
\hline Affection & $\mathrm{n}$ & $\%$ \\
\hline Aortic & 33 & \\
Aortic stenosis & 25 & 75 \\
Aortic failure & 4 & 12 \\
Duble aortic lesion & 3 & 10 \\
Subaortic membrane & 1 & 3 \\
Mitral & 36 & \\
Mitral stenosis & 7 & 19 \\
Mitral failure & 20 & 56 \\
Double mitral lesion & 8 & 22 \\
Prosthesis failure & 1 & 3 \\
ASD & 25 & \\
Ostium primum & 1 & 4 \\
Ostium secundum & 21 & 84 \\
Sinus venosus & 3 & 12 \\
Left atrial myxoma & 2 & 100 \\
& & \\
Etiology & $\mathrm{n}$ & $\%$ \\
Aortic & 33 & \\
Bicuspid aortic valve & 3 & 9 \\
Calcific degeneration & 24 & 72 \\
Aortic anuloectasia & 1 & 3 \\
Rheumatic & 4 & 13 \\
Congenital & 1 & 3 \\
Mitral & 36 & \\
Rheumatic & 22 & 61 \\
Myxomatous & 13 & 36 \\
Dilated cardiomyopathy & 1 & 3 \\
ASD & 25 & \\
Congenital & 25 & 100 \\
Left atrial myxoma & 2 & 100 \\
\hline ASD atral septal & & \\
& 12 & \\
& & \\
& &
\end{tabular}

$A S D=$ atrial septal defects

\section{Preoperative assessment}

All patients were assessed with clinical examination, electrocardiogram, chest X-ray and two-dimensional Doppler echocardiogram. In patients older than 40 years, coronary angiography was performed to exclude the presence of associated coronary artery.

Whenever possible, chest and abdomen contrast angiography was performed to study in detail the anatomic relationships of cardiac structures in relation to the thoracic cavity, as well as to assess the presence of atheromatous disease in the thoracic and abdominal aorta and iliac and femoral vessels. In younger patients, however, this assessment can be performed with peripheral vascular ultrasound.

In all cases the decision to perform minimally invasive procedure has been previously discussed with each patient individually. 


\section{Surgical technique}

Despite the technical aspects have been improved throughout the experiment, and some variation due to the type of surgery to be performed, the general principles are similar in all cases.

Anesthesia was performed with conventional intubation, without making use of selective pulmonary ventilation. Where available, we used intraoperative transesophageal echocardiography (TEE) to monitor the proper placement of arterial and venous cannulae during cardiopulmonary bypass (CPB), as well as to guide the surgeon in some specific moments of the surgery, such as during infusion cardioplegic solution, remove air from the cardiac chambers after CPB and assessment of ventricular function postoperatively.

In 89 patients, a $3 \mathrm{~cm}$ incision was performed in the inguinal region and the $\mathrm{CPB}$ was established by retrograde perfusion with cannulation under direct visualization of the femoral vessels. In the remaining patients, arterial cannulation was performed directly in the ascending aorta, and venous drainage performed by the right atrium or femoral vein puncture. CPB was used with moderate hypothermia at $32^{\circ} \mathrm{C}$, with the aid of vacuum to optimize

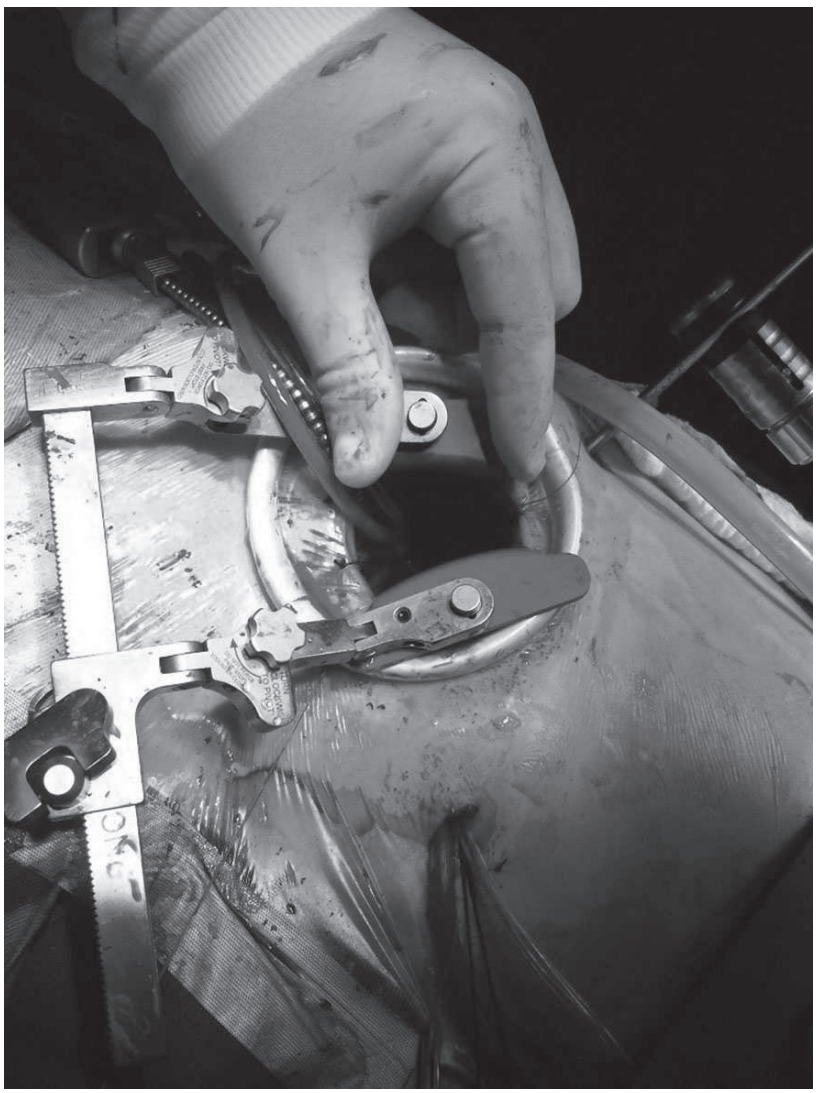

Fig. 1 - Surgical access by lateral minithoracotomy venous drainage. Myocardial protection was achieved using cold blood cardioplegia in 89 patients, and Custodiol ${ }^{\circledR}$ solution in six cases. The aortic clamping was performed using retractable clamp.

In 87 patients, surgical access was performed using side mini-thoracotomy (Figure 1), and 8 cases using ministernotomy. In mitral patients or for closing ASDs, the incision was performed on the 4th right intercostal space (RICS), in the inframammary region, located between the anterior and middle axillary lines. As for the aortic patients, the minithoracotomy was anterior, intercostal, at 2nd or 3rd RICS, performing the ligation of right internal thoracic artery and usually with temporary detachment of the condrocostal junction of the inferior or superior rib to facilitate exposure of the aortic root. In all cases, we used a chest auxiliary contraincision, $1 \mathrm{~cm}$ long, which were passed a left ventricular drainage cannula, a catheter for continuous $\mathrm{CO}_{2}$ insufflation into the pleural cavity, in addition to some points of pericardium exposure. At the end of the procedure, this small incision is used for the passage of the chest tube.

The surgical technique for valve replacement or repair surgeries, closure of ASDs or resection of tumors were similar to those employed in conventional surgeries.

\section{Postoperative assessment}

We assessed the results in the immediate postoperative period until the time of hospital discharge. Specifically, we study the immediate mortality, defined as any death within 30 postoperative days or before hospital discharge, and postoperative complications, including the need for reoperations, total amount of bleeding and need for blood transfusion, length of stay in intensive care unit (ICU) and hospital stay length.

\section{RESULTS}

Our initial series with minimally invasive surgeries involved the implementation of correction of ASD $(n=24)$, aortic valve replacement $(n=33)$, mitral valve replacement $(\mathrm{n}=12)$, mitral valve repair $(\mathrm{n}=24)$ resection left atrial myxoma $(n=2)$ and subaortic membrane resection $(n=1)$. The details of the surgeries performed are listed in Table 3.

The aortic clamping time ranged from 18 to $117 \mathrm{~min}$ (mean $60 \pm 25 \mathrm{~min}$ ) and total $\mathrm{CPB}$ time ranged from 50 to $180 \mathrm{~min}$ (mean $=96 \pm 34 \mathrm{~min})$. In most patients $(\mathrm{n}=87)$, surgeries were performed using side minithoracotomies, whose extension ranged from 4 to $10 \mathrm{~cm}(6.3 \pm 1.2 \mathrm{~cm})$.

Hospital mortality was of four (4.2\%) cases. The causes of death were sepsis with multiple organ failure in two aortic elderly patients, low output syndrome in a patient with mitral regurgitation by dilated cardiomyopathy and mesenteric thrombosis in the latter case (Table 4). 
Table 3. Operative data

\begin{tabular}{|c|c|c|}
\hline \multirow{2}{*}{$\begin{array}{l}\text { No. of patients } \\
\text { Surgery performed }\end{array}$} & \multicolumn{2}{|c|}{95} \\
\hline & \multirow{2}{*}{\multicolumn{2}{|c|}{24}} \\
\hline Atrial septal defect & & \\
\hline Continuous suture & 4 & $16 \%$ \\
\hline Bovine pericardium patch & 20 & $84 \%$ \\
\hline Atrial myxoma & 2 & $100 \%$ \\
\hline Mitral repair & \multicolumn{2}{|l|}{23} \\
\hline Bovine pericardium ring & 6 & $27 \%$ \\
\hline Gregori's ring & 1 & $4 \%$ \\
\hline Carpentier's ring & 1 & $4 \%$ \\
\hline Commissurotomy & 4 & $17 \%$ \\
\hline Commissurotomy + bovine pericardium ring & 2 & $8 \%$ \\
\hline Quadrantectomy + bovine pericardium ring & 14 & $60 \%$ \\
\hline Mitral repair + ASD & \multicolumn{2}{|l|}{1} \\
\hline Commissurotomy + bovine pericardial patch & 1 & $100 \%$ \\
\hline Mitral valve repair & \multicolumn{2}{|l|}{12} \\
\hline Biological prosthesis & \multicolumn{2}{|r|}{$91 \%$} \\
\hline Metalic prosthesis & 1 & $9 \%$ \\
\hline Aortic valve replacement & \multicolumn{2}{|l|}{32} \\
\hline Biological prosthesis & \multicolumn{2}{|r|}{$100 \%$} \\
\hline Subaortic membrane & \multirow{2}{*}{\multicolumn{2}{|c|}{$100 \%$}} \\
\hline Incision site & & \\
\hline 2nd right intercostal space & 13 & $14 \%$ \\
\hline 3 rd right intercostal space & 24 & $26 \%$ \\
\hline 4 th right intercostal space & 42 & $44 \%$ \\
\hline 5 th right intercostal space & 8 & $8 \%$ \\
\hline Ministernotomy & 8 & $8 \%$ \\
\hline Incision size & \multicolumn{2}{|c|}{$6.34 \pm 1.2 \mathrm{~cm}$} \\
\hline \multicolumn{3}{|l|}{ Type cannulation } \\
\hline Aorta and right atrium & 5 & $5 \%$ \\
\hline Aorta and femoral vein & 1 & $1 \%$ \\
\hline Artery and femoral vein & 86 & $91 \%$ \\
\hline Artery and femoral vein, internal jugular vein & 3 & $3 \%$ \\
\hline \multicolumn{3}{|l|}{ Type of myocardial protection } \\
\hline Antegrade cold blood & $5 \%$ & $92 \%$ \\
\hline Custodiol & $1 \%$ & $7 \%$ \\
\hline Retrograde cold blood & $91 \%$ & $1 \%$ \\
\hline Aortic clamping time (mean \pm SD) & \multicolumn{2}{|c|}{$60.5 \pm 25.4 \mathrm{~min}$} \\
\hline Time of DPB (mean \pm SD) & \multicolumn{2}{|c|}{$96.4 \pm 34.2 \mathrm{~min}$} \\
\hline
\end{tabular}

$A S D=$ atrial septal defect. $S D=$ standard deviation

Table 4. Immediate mortality in 95 patients who underwent minimally invasive surgeries

\begin{tabular}{lc}
\hline Mortality & \\
\hline No. of deaths & $4(4.2 \%)$ \\
Deaths in the immediate postoperative & 2 \\
Aortic valve replacement & 1 \\
Mitral valve replacement & 1 \\
Mitral repair & \\
Causes of death & 2 \\
Sepsis & 1 \\
Acute abdomen & 1 \\
Low output syndrome & \\
\hline
\end{tabular}

In the intraoperative period, we had three cases with lesions in cardiac structures requiring additional correction. During weaning from $\mathrm{CPB}$, a patient presented bleeding in the pericardial cavity, which forced us to enlarge the incision with transverse section of the sternum and extending of the thoracotomy up the left side of the chest, to correct traumatic bleeding in the left atrium, with good evolution. Two patients had mitral perforations in the right ventricle, one caused by the tip of the venous cannula and another by electrode of previously implanted pacemaker. In both cases, the lesions occurred during retraction of the left atrium, and were readily identified before discontinuing $\mathrm{CPB}$, and could be corrected successfully without need to extend minithoracotomy.

Among the common postoperative morbidities, we had the low output syndrome in $15 \%$ of cases and occurrence of paroxysmal atrial fibrillation in $14 \%$ of patients. In $67 \%$ of cases, there were no complications. In no patient wound infection was found. Despite not having an objective assessment of postoperative pain, patients subjectively reported only discomfort and pain in the chest considered as mild and bearable. The degree of satisfaction with the end cosmetic results are invariably high (Figure 2). Among the serious complications, two patients had cerebrovascular accident (CVA), of which one was transient and with complete reversal and the second patient presented sequelae due to extensive ischemic lesion in the left temporal lobe. Severe respiratory failure requiring tracheostomy occurred in 1 patient, and transient renal insufficiency was detected in six patients, however, without the need for dialysis in any of them (Table 5).

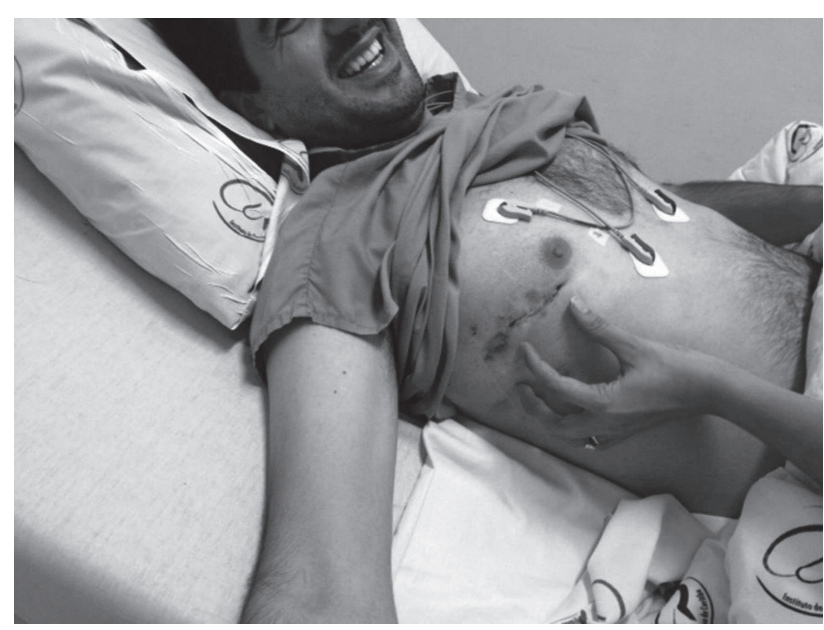

Fig. 2 - Patient demonstrates satisfaction with end cosmetic results 
Table 5. Operative and postoperative morbidity in 95 patients undergoing minimally invasive surgeries.

\begin{tabular}{lcc}
\hline No. of patients & \multicolumn{2}{c}{95} \\
\hline Operative morbidity & & \\
Need for conversion to conventional thoracotomy & 1 & $1 \%$ \\
Blood transfusion & 74 & $77 \%$ \\
Number of bags transfused (mean \pm SD) & $1.65 \pm 1.62$ \\
Drains bleeding (mean \pm SD) & $470 \pm 277 \mathrm{ml}$ \\
Days of hospitalization in ICU (mean \pm SD) & $2.8 \pm 1.7$ \\
Days of hospitalization (mean \pm SD) & $8.7 \pm 4.5$ \\
Postoperative morbidity & & \\
New Atrial fibrillation & 13 & $14 \%$ \\
Low output syndrome & 14 & $15 \%$ \\
Intra-aortic balloon & 4 & $4 \%$ \\
Reoperation for bleeding & 2 & $2 \%$ \\
Respiratory failure & 2 & $2 \%$ \\
Tracheostomy & 1 & $1 \%$ \\
Pneumonia & 5 & $5 \%$ \\
Renal failure & 6 & $6 \%$ \\
AMI & 2 & $2 \%$ \\
CVA & 2 & $2 \%$ \\
Acute abdomen & 1 & $1 \%$ \\
Surgical site infection & 0 & $0 \%$ \\
No complication & 64 & $67 \%$ \\
\hline
\end{tabular}

$C V A=$ stroke. $S D=$ standard deviation. $. M I=$ myocardial infarction. ICU = intensive care unit

The total bleeding postoperatively ranged from 50 to $3400 \mathrm{ml}$ (mean=470 $\pm 277 \mathrm{ml})$, and blood transfusion was performed on 74 patients who received an average of $1.6 \pm$ 1 units of PRBC. Only two patients underwent reoperation for excessive bleeding, being possible correction through the same incision of the original transaction.

The length of stay in the ICU ranged from 12 hours to 13 days (mean $=2.8 \pm 1.7$ days) and length of hospitalization ranged from 4 to 30 days (mean $=8.7 \pm 4.5$ days).

For clinical and echocardiographic assessment, surgical corrections were considered satisfactory. All ASDs were properly closed, and in patients with prosthetic heart valves, no importante paravalve leaks were detected. Similarly, patients undergoing mitral valve repair remained with competent valves or backflow graded as trivial.

\section{DISCUSSION}

Minimally invasive surgeries have been performed since the early 1990s, however, because they are technically more elaborate and require specific training, their acceptance is still limited. Data from the Society of Thoracic Surgery (STS) show that less than $20 \%$ of valve surgeries are performed by minimally invasive incisions, and there are few centers that make these surgeries more routine $[1,2,9]$. In our country, that number should be even lower, given the small number of publications on minimally invasive valve surgery, and with relatively small case series [10-13]. Among the major experiments, Poffo et al. [10] reported a case series of 102 patients who underwent surgery between 2006 and 2008, and more recently. Junior Fortunato et al. [12] reported the results of 136 patients who underwent surgery over 6 years.

The minimally invasive surgeries are performed in order to reduce operative trauma and possibly reduce the risk of morbidity and mortality. However, the results currently available do not prove unequivocally, objective benefits that justify the wider application of these techniques $[14,15]$. More recently, however, some studies suggest decreased mortality in some specific subgroups of patients, such as in mitral reoperations, obese and aortic or elderly [16-19].

The results of our initial series with minimally invasive surgeries confirm the observations of other authors that, in selected cases, plasty or valve replacement surgeries, correction of some congenital heart disease and atrial myxoma resection can be performed safely and with mortality rates comparable to those obtained through conventional sternotomy $[3,11]$. Despite not having a control group and this study not being comparative, no immediate deaths in this series can be attributed to complications related to the technique.

Several incisions have been advocated for performing minimally invasive procedures, including some variants of upper and lower ministernotomy, anterior or side minithoracotomies, and may be performed either on the right or left side of the chest [11.20-22]. Although some cases of aortic prosthesis in our series were performed using upper ministernotomy, our preference has been present for intercostal minithoracotomy whenever possible.

There is difficulty in defining what is called minimally invasive cardiac surgery. A careful reading of the published study, as well as the observation of surgeries performed in several centers, shows that these surgeries range from those with relatively large incisions in the skin, with 8 to 10 $\mathrm{cm}$ in length, but with extensive dissection of the intercostal spaces and with remoteness and trauma pronounced in the ribs, and also surgeries with smaller incisions of 3-4 cm with minimal dissection, with exclusive use of retractors and soft tissue with the aid of video equipment or robotic systems [5,6]. Thus, comparison of results between different services becomes complex and difficult to interpret.

When we started our experience of valve surgeries with small thoracotomies, we are fully aware that they involve a learning curve and that patient selection, as well as a gradual evolution in reducing the size of the incision should be made with caution $[1,6]$. Thus, in initial cases we used incisions around $8-10 \mathrm{~cm}$ long, but, as the technique has been refined, this size may be reduced to incisions which 
typically range from 4 to $6 \mathrm{~cm}$ in recent patients. With the development of the technique, our dissection of the intercostal spaces is minimal and corresponding for the size of the incision in the skin, and the removal of the intercostal space is limited, avoiding trauma to the ribs and thereby decreasing postoperative pain.

Some centers advocate the use of video or robotic systems for performing these surgeries [4,9,11]. In Brazil, Poffo et al. [11] reported their experience of minimally invasive surgeries with the aid of video, including being performed a pioneering procedure by periareolar access. However, these surgeries are more complex and, even with the use of sophisticated technologies, there is a need for an incision of at least 3 to $4 \mathrm{~cm}$ in length, and some additional small incisions that serve as entry to the additional equipment without taking into account the high costs. The techniques employed allow us to perform the entire surgery under direct vision with incisions that are no more than 1 to $2 \mathrm{~cm}$ longer, being more accessible to groups who want to start with these procedures.

Patient selection for minimally invasive surgeries should be cautious and, in our opinion, can only be extended as it exceeds the initial learning curve. We find no justifiable decreasing the size of the incision to the detriment of the quality of the technique [8]. Thus, it should start with the simplest cases and with favorable anatomy, preventing cases of complex mitral repair or patients with unfavorable aortic root and with extreme calcification. In addition, some factors constitute relative or absolute contraindications for this type of surgery, such as important peripheral vascular disease, right thoracotomy and/or previous thoracic irradiation, concomitant need for surgeries such as coronary artery bypass grafting and thoracic deformities such as pectus excavatum [15].

Some technical aspects seem to be important for obtaining consistently satisfactory results. For anesthesia, the selective intubation should be avoided, since the possibility of occurrence of unilateral pulmonary edema which is a complication of complex handling [23]. The use of TEE is essential for the proper positioning of the arterial, venous and retrograde cardioplegia cannulas, as well as for monitoring various steps of the surgery, during the removal of air from the heart chambers and to monitor ventricular function and appropriate management of inotropic drugs, since we have no visualization of the heart as in the conventional surgeries [7,9]. In our series, we had a case of injury to the right ventricle through the tip of the venous cannula that could have been avoided with proper TEE control which was not available in this case.

The potential need for conversion to median thoracotomy has been reported in most published studies, being caused mainly when there is the occurrence of acute aortic dissection or rupture of the atrioventricular groove
[15]. In our initial series, in the only case with inaccessible bleeding, we performed an extension of thoracotomy on the left side of the chest to suture the tip of the left atrium that had been traumatized during aortic clamping.

Some studies suggest that performing minimally invasive surgeries can be associated with a higher incidence of stroke. Among the risk factors for this complication are older age, atheromatous aorta with diffuse retrograde arterial perfusion, using endoclamps or perform the operation without aortic clamping during the heart fibrillating[1]. For this reason, we think that the retrograde CPB by femoral vessels should be preceded by extensive preoperative assessment, and should be avoided in cases of diffuse atherosclerotic disease of the aorta, iliac or femoral arteries, as well as in patients with femoral vessels of small caliber. Alternatively, there is the possibility of axillary artery cannulation in selected cases, also the ascending aortic cannulation, as recommended by Crooke et al [16]. In our experience, we use retrograde perfusion in all cases where the incision was performed by side minithoracotomy, and the aortic clamping performed using retractable clamp. In cases where there was more pronounced aortic atheromatosis, surgeries were performed by ministernotomy and central arterial cannulation. With this methodology, our incidence of stroke was two (2\%) cases, both in elderly aortic patients. There were no major brain complications in any mitral or ASD patient.

The venous drainage performed with the aid of vacuum is usually adequate, however, in cases where the right side of the heart is approached, or when the drainage is poor, placing a second cannula, both by venipuncture directly into the internal jugular or cava above should be performed. [5]

A possible criticism of minimally invasive surgeries refers to longer times of aortic clamping and CPB. In our experience, aortic clamping, although longer than in conventional surgeries, was within a range of time quite reasonable, and apparently caused no increase in inflammatory response nor disturbances in blood clotting [24].

The average amount of total bleeding of $470 \mathrm{ml}$ can be considered low, comparing favorably with other published series $[15,18]$. Still, $70 \%$ of our patients received at least one unit of blood transfusion, suggesting the need for more stringent treatment protocols in the immediate postoperative period in our institution. Similarly, the incidence of reoperation for bleeding was low and, in both cases, the source of the bleeding was coming from the thoracic wall, which reinforces the need for detailed review of hemostasis, since the view of the intercostal spaces is very limited with this type of incision [15].

Although this study is not comparative, subjective impression was that the patients presented easier 
postoperative functional recovery, with ambulation and earlier return to daily activities compared with those patients undergoing surgeries involving medians thoracotomy. The level of personal satisfaction with the incision and the cosmetic aspects was also high.

\section{Limitations of the Study}

This study aimed to report our initial experience with valve surgeries and congenital heart disease with minimally invasive techniques. The number of cases undergone this type of surgery is still quite limited, and as it is not a comparative study, we can not make definitive inferences about their possible indications and about their real advantages and disadvantages.

\section{CONCLUSIONS}

Our experience shows that valve surgeries, of correction of simple congenital heart disease and cardiac tumor resection can be performed safely and with results similar to those obtained with conventional techniques. The incidence of stroke was $2 \%$, and postoperative morbidity was low. In addition, the functional recovery of patients is faster and satisfaction on the part of patients is at least subjectively better. Once overcome the learning curve and proper training of all staff involved, minimally invasive surgeries can become an attractive option for many patients with these conditions.

\section{REFERENCES}

1. Gammie JS, Zhao Y, Peterson ED, O'Brien SM, Rankin JS, Griffith BP. J. Maxwell Chamberlain Memorial Paper for adult cardiac surgery. Less-invasive mitral valve operations: trends and outcomes from the Society of Thoracic Surgeons Adult Cardiac Surgery Database. Ann Thorac Surg. 2010;90(5):1401-8.
2. Cheng DC, Martin J, Lal A, Diegeler A, Folliguet TA, Nifong LW, et al. Minimally invasive versus conventional open mitral valve surgery: a meta-analysis and systematic review. Innovations (Phila). 2011;6(2):84-103.

3. Falk V, Cheng DC, Martin J, Diegeler A, Folliguet TA, Nifong LW, et al. Minimally invasive versus open mitral valve surgery: a consensus statement of the international society of minimally invasive coronary surgery (ISMICS) 2010. Innovations (Phila). 2011;6(2):66-76.

4. Gao C, Yang M, Xiao C, Wang G, Wu Y, Wang J, et al. Robotically assisted mitral valve replacement. J Thorac Cardiovasc Surg. 2012;143(4 Suppl):S64-7.

5. Woo YJ, Seeburger J, Mohr FW. Minimally invasive valve surgery. Semin Thorac Cardiovasc Surg. 2007;19(4):289-98.

6. Casselman FP, Van Slycke S, Wellens F, De Geest R, Degrieck I, Vermeulen Y, et al. From classical sternotomy to truly endoscopic mitral valve surgery: a step by step procedure. Heart Lung Circ. 2003;12(3):172-7.

7. Glauber M, Miceli A, Bevilacqua S, Farneti PA. Minimally invasive aortic valve replacement via right anterior minithoracotomy: early outcomes and midterm follow-up. J Thorac Cardiovasc Surg. 2011;142(6):1577-9.

8. Anyanwu AC, Adams DH. Should complex mitral valve repair be routinely performed using a minimally invasive approach? Curr Opin Cardiol. 2012;27(2):118-24.

9. Casselman FP, Van Slycke S, Wellens F, De Geest R, Degrieck I, Van Praet F, et al. Mitral valve surgery can now routinely be performed endoscopically. Circulation. 2003;108 Suppl 1:II48-54.

10. Poffo R, Pope RB, Selbach RA, Mokross CA, Fukuti F, Silva Júnior I, et al. Video-assisted cardiac surgery: results from a pioneer project in Brazil. Rev Bras Cir Cardiovasc. 2009;24(3):318-26.

11. Poffo R, Pope RB, Toschi AP, Mokross CA. Video-assisted minimally invasive mitral valve repair: periareolar approach. Rev Bras Cir Cardiovasc. 2009;24(3):425-7.

12. Fortunato Jr JA, Pereira ML, Martins ALM, Pereira DSC, Paz MA, Paludo L, et al. Cirurgia cardíaca video-assistida. Rev Bras Cir Cardiovasc. 2012;27(1):24-37.

13. Dias RR, Sobral MLP, Avelar Jr SF, Santos GG, Lima MAVB, Haddad V, et al. Cirurgia da valva aórtica: estudo prospectivo e randomizado da miniesternotomia versus esternotomia convencional. Rev Bras Cir Cardiovasc. 1999;14(2):98-104.

14. Speziale G, Nasso G, Esposito G, Conte M, Greco E, Fattouch $\mathrm{K}$, et al. Results of mitral valve repair for Barlow disease (bileaflet prolapse) via right minithoracotomy versus conventional median sternotomy: a randomized trial. J Thorac Cardiovasc Surg. 2011;142(1):77-83. 
15. Modi P, Rodriguez E, Hargrove WC 3rd, Hassan A, Szeto WY, Chitwood WR Jr. Minimally invasive video-assisted mitral valve surgery: a 12-year, 2-center experience in 1178 patients. J Thorac Cardiovasc Surg. 2009;137(6):1481-7.

16. Crooke GA, Schwartz CF, Ribakove GH, Ursomanno P, Gogoladze G, Culliford AT, et al. Retrograde arterial perfusion, not incision location, significantly increases the risk of stroke in reoperative mitral valve procedures. Ann Thorac Surg. 2010;89(3):723-9.

17. Sansone F, Punta G, Parisi F, Dato GM, Zingarelli E, Flocco R, et al. Right minithoracotomy versus full sternotomy for the aortic valve replacement: preliminary results. Heart Lung Circ. 2012;21(3):169-73.

18. Santana O, Reyna J, Grana R, Buendia M, Lamas GA, Lamelas J. Outcomes of minimally invasive valve surgery versus standard sternotomy in obese patients undergoing isolated valve surgery. Ann Thorac Surg. 2011;91(2):406-10.

19. Mihos CG, Santana O, Lamas GA, Lamelas J. Outcomes of right minithoracotomy mitral valve surgery in patients with previous sternotomy. Ann Thorac Surg. 2011;91(6):1824-7.

20. Saunders PC, Grossi EA, Sharony R, Schwartz CF, Ribakove $\mathrm{GH}$, Culliford AT, et al. Minimally invasive technology for mitral valve surgery via left thoracotomy: experience with forty cases. J Thorac Cardiovasc Surg. 2004;127(4):1026-31.

21. Svensson LG. Minimal-access "J" or "j" sternotomy for valvular, aortic, and coronary operations or reoperations. Ann Thorac Surg. 1997;64(5):1501-3.

22. Svensson LG. Minimally invasive surgery with a partial sternotomy "J" approach. Semin Thorac Cardiovasc Surg. 2007;19(4):299-303.

23. Madershahian N, Wippermann J, Sindhu D, Wahlers T. Unilateral re-expansion pulmonary edema: a rare complication following one-lung ventilation for minimal invasive mitral valve reconstruction. J Card Surg. 2009;24(6):693-4.

24. Brinkman WT, Hoffman W, Dewey TM, Culica D, Prince SL, Herbert MA, et al. Aortic valve replacement surgery: comparison of outcomes in matched sternotomy and PORT ACCESS groups. Ann Thorac Surg. 2010;90(1):131-5. 